\title{
Existence of Periodic Solutions for a Class of Fourth-order Difference Equation
}

\author{
Xiaoling $\operatorname{Han}^{1}$ and fumei ye ${ }^{1}$ \\ ${ }^{1}$ Northwest Normal University
}

November 6, 2020

\begin{abstract}
We apply the continuation theorem of Mawhin to ensure that a fourth-order nonlinear difference equation of the form $\$ \$ \backslash D$ Delta^ 4 $\mathrm{u}(\mathrm{k}-2)-\mathrm{a}(\mathrm{k}) \mathrm{u}^{\wedge}\{\backslash \mathrm{alpha}\}(\mathrm{k})+\mathrm{b}(\mathrm{k}) \mathrm{u}^{\wedge}\{\backslash$ beta $\}(\mathrm{k})=0, \$ \$$ with periodic boundary conditions possesses at least one nontrivial positive solution, where $\$ \backslash$ Delta $u(k)=u(k+1)-u(k) \$$ is the forward difference operator, $\$ \backslash$ alpha, $\backslash$ beta $\backslash$ in $\backslash$ mathbb $\{\mathrm{N}\}^{\wedge}+\$$ and $\$ \backslash$ alpha $\backslash$ neq $\backslash$ beta $\$$. $\$ a(k), b(k) \$$ are $\$ \mathrm{~T} \$$-periodic functions and $\$ \mathrm{a}(\mathrm{k}) \mathrm{b}(\mathrm{k})>0 \$$. As applications, we will give some examples to illustrate the application of these theorems.
\end{abstract}

\section{Hosted file}

fourth-order discrete problem.pdf available at https://authorea.com/users/373643/articles/ 491272-existence-of-periodic-solutions-for-a-class-of-fourth-order-difference-equation 